\title{
A Multi-period Supply Network of Food Products Based on Time-Windows with Sensitivity Analysis
}

\author{
Zeynab Raftani-Amiri \\ Sari Agricultural Sciences and Natural Resources University, P.O.Box 578, Sari, Iran \\ Email*: irajarash@rediffmail.com \\ Hamed Fazlollahtabar \\ Department of Industrial Engineering, Mazandaran University of Science and Technology, Babol, Iran \\ Email: hamed@ustmb.ac.ir \\ Nezam Mahdavi-Amiri \\ Faculty of Mathematical Sciences, Sharif University of Technology, Tehran, Iran \\ Email: nezamm@sharif.edu
}

\begin{abstract}
Supply chain management is a cross-function approach to manage the movement of products toward consumers. Here, we propose a supply network which considers multiple food products with time windows. The proposed model considers different customers who are serviced by one supplier. The supplier provides various products being kept in different depots. Each depot uses different types of vehicles to satisfy the orders. Initially, all depots are stationed at the designated locations. The applicability of the model is illustrated using a numerical experiment. A comprehensive sensitivity analysis is worked out to show the flexibility of the proposed mathematical model.
\end{abstract}

Keywords: : supply network, food products, time window, multi period

\section{Introduction}

The agro-food industry is a sector of significant economic and political importance. It is one of the most regulated and protected sectors. As a result of intensive development in the past century, food production has been continuously putting increasing pressure on the environment, and thus increasingly attracting the attention of policy makers.

Supply chain coordination has gained a considerable notice recently from both practitioners and researchers. In monopolistic markets with a single chain or markets with perfect competing retailers, a vertically integrated supply chain maximizes the profit of the chain (e.g., Jeuland and Shugan, 1983; Cachon and Lariviere, 2005; Bernstein and Federgruen, 2005). Therefore, many supply chain contracts try to induce retailers and suppliers to act according to the vertical integration strategy.

Consumers today demand high-quality products in various innovative forms through the entire year at competitive prices. Society imposes constraints on producers in order to economize the use of resources, ensure animal friendly and safe production practices and restrict environmental damage. These demands, together with advancing technology and presence of 
open markets have changed the production, trade and distribution, namely the supply chain of food products beyond recognition (Trienekens and Omta, 2001).

A supply chain (SC) is an integrated process in which raw materials are acquired, converted into products and then delivered to the consumer (Beamon, 1998). The chain is characterized by a forward flow of goods and a backward flow of information. Food supply chains are made up of organizations that are involved in the production and distribution of plant and animal-based products (Zuurbier et al., 1996). Such SCs can be divided into two main types (van der Vorst, 2000):

- SCs for fresh agricultural products: the intrinsic characteristics of the product remain unchanged, and

- SCs for processed food products: agricultural products are used as raw materials to produce processed products with a higher added value.

The main fact that differentiates food SCs from other chains is that there is a continuous change in quality from the time the raw material leaves the grower to the time the product reaches the consumer (Tijskens et al., 2001). The food SC being considered here consists of six links: primary producers, ingredient preparations, product processings, distributions, retailers and consumers (see Figure 1).
Performance measures or goals are considered to design SCs or supply networks by determining the values of the decision variables that yield the desired goals or performance levels (Apaiah et al., 2005; Beamon, 1998). The design of the chain or network changes in accordance with the goal for which the chain is being designed and optimized. Since consumer demands have to be met, it is important to ask the consumer what attributes he/she desires in the product to be considered in achieving the goals to design the chain; e.g., if the goal is quality at any cost, then technologically advanced and consequently expensive equipments can be used to produce the product and it can be transported to the consumer by air for fast delivery. However, if the goal is a low priced product, care has to be taken to minimize production and transportation costs.

A market with two competing supply chains was investigated in the seminal work of McGuire and Staelin (1983). They considered a price (i.e., Bertrand) competition between two suppliers selling through independent retailers. They concluded that for highly substitutable products a decentralized supply chain Nash equilibrium was preferred by both suppliers. In Coughlan (1985), the author applied this work to the electrical industry and Moorthy (1988) further explained why the decentralized chains could lead to

Figure 1. A food supply chain

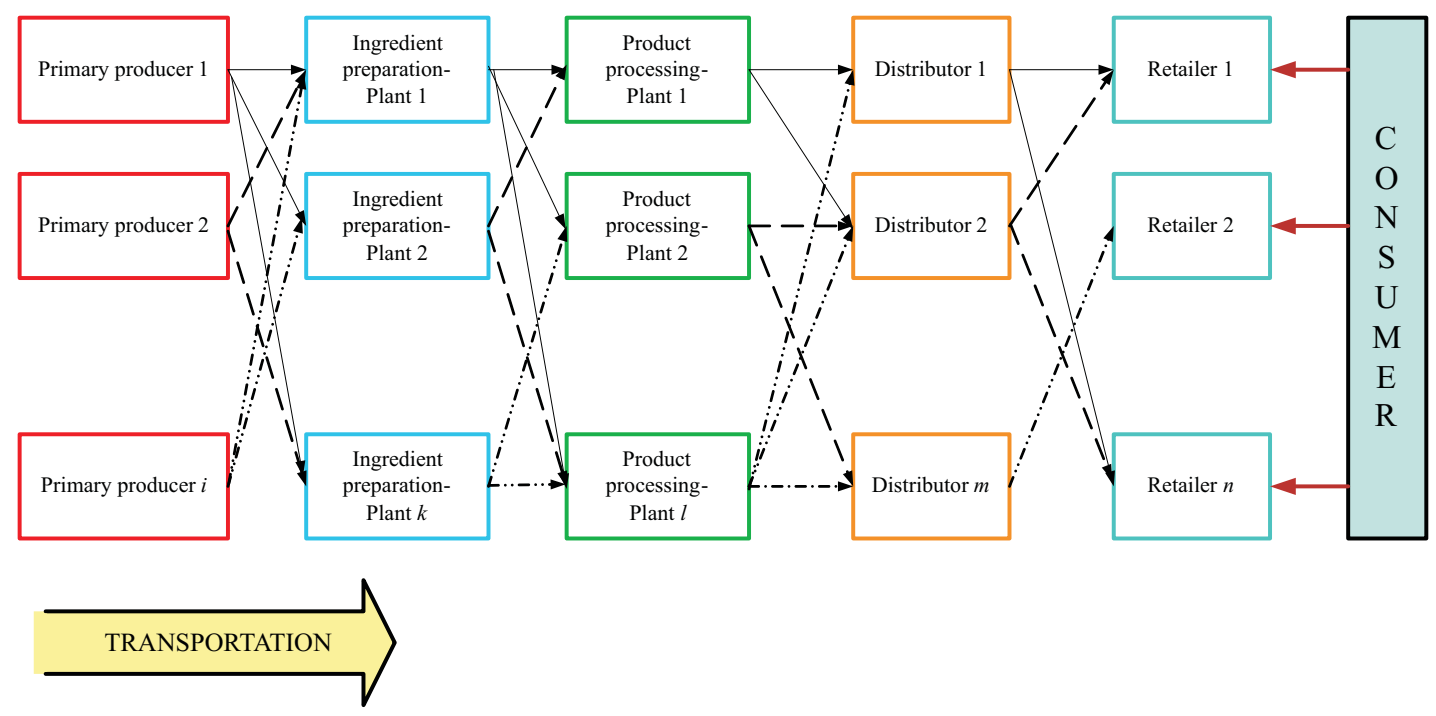


higher profits for the manufacturer and the entire chains. In Bonanno and Vickers (1988), the authors investigated a similar model, and used geometric insights to show that with franchise fees there were some settings in which the manufacturer's optimal strategy was to sell his products using an independent retailer. Thus, in these cases, the manufacturer prefers a decentralized supply chain irrespective of the decision in the other supply chain. Neither of these works considered demand uncertainty.

Product specifications have been studied as supplier allocation in supply networks ( $\mathrm{Xu}$ and Nozick, 2009). Christopher et al. (2009) studied the effects of innovation and knowledge in the supply chain performance. They concluded to a knowledge based mechanism for order allocation to suppliers. Also, product allocation in supply network was presented by Francasa and Minner (2009). They found out that back order products could be allocated to manufacturing element of a supply network. Order and reorder placements using intelligent agents were studied by Pan et al. (2009). He explored the elements of an intelligent agent for order allocation. Che et al. (2009) proposed a line balancing based model for supplier allocation. They proposed a line balancing technique to assign supplying activities to the supply network elements and order allocation.

The supply chain problem is of an utmost economic importance to businesses due to the elapsing times and costs associated with the provision of a fleet of delivery vehicles for transportation of products to a set of geographically dispersed customers (Pasternack, 1985). Moreover, such problems are also significant in the public sector, where vehicle routes must be determined for bus systems, postal carriers, and other public service vehicles. In each of these instances, the problem typically involves finding a minimal cost of the combined routes for a number of vehicles in order to facilitate delivery from a supply location to a number of customer locations. Since cost is closely associated with distance, a company might attempt to find a minimal distance traveled by the vehicles in order to satisfy customer demands. In doing so, the firm attempts to minimize costs while elevating or at least maintaining an expected level of customer service. The remainder of our work is organized as follows. In Section 2, we give a comprehensive description of food products and their importance. Section 3 presents the configuration of food supply chains. In Section 4, the proposed problem and the mathematical model is described. The validity and applicability of the mathematical model is tested by a numerical illustration in Section 5. In Section 6, the flexibility of the model is shown through a comprehensive sensitivity analysis. We conclude in Section 7 .

\section{Food Products}

The food industry is a complex, global array of diverse businesses that collectively supplies much of the food energy consumed by the world population. Only subsistence farmers, those who survive on what they grow, can be considered outside of the scope of the modern food industry. The following aspects are associated with the food industry.

- Regulation: local, regional, national and international rules and regulations for food production and sale, including food quality and food safety, and industry lobbying activities.

- Education: academic, vocational, and consultancy.

- Research and development: food technology.

- Manufacturing: agrichemicals, seed, farm machinery and supplies, agricultural construction, etc.

- Agriculture: raising of crops and livestock, and seafood.

- Food processing: preparation of fresh products for market, and manufacture of prepared food products.

- Marketing: promotion of generic products (e.g., milk board), new products, public opinion, through advertising, packaging, public relations, etc.

- Wholesale and distribution: warehousing, transportation, and logistics.

- Retail: supermarket chains and independent food stores, direct-to-consumer, restaurant, food services

Vast global transportation network is required by the food industry in order to connect its numerous parts. These include suppliers, manufacturers, warehousing, retailers and the end consumers. There 
are also companies that, during the food processing process, add vitamins, minerals, and other necessary requirements usually lost during the food preparation. Wholesale markets for fresh food products have tended to decline in importance in some countries as well as in Latin America and some Asian countries as a result of the growth of supermarkets, which procure directly from farmers or through preferred suppliers, rather than going through markets.

The constant and uninterrupted flow of products from distribution centers to store locations is a critical element of food industry operations. Distribution centers run more efficiently, the throughput can be increased, costs can be lowered, and manpower can be better utilized if proper steps are taken in setting up a material handling system in a warehouse. With populations around the world being concentrated in urban areas, purchasing food is increasingly removed from all aspects of food production. This is a relatively recent development, taking place mainly over the past 50 years. Supermarkets are defining retail elements of the food industry, whereas tens of thousands of products are gathered in diverse locations, with continuous, year-round supplies.

Food preparation is another area for which change in recent decades has been dramatic. Today, two food industry sectors are in apparent competition for the retail food values. The grocery industry sells fresh and largely raw products for consumers to be used as ingredients in home cooking. The food service industry offers prepared food, either as finished products, or as partially prepared components for final "assembly".

Sophisticated technologies define modern food production. They include many areas. Agricultural machinery, originally led by tractors, has practically eliminated human labor in many areas of production. Biotechnology is driving much change in areas as diverse as agrochemicals, plant breeding and food processing. Many other aspects of technology are also involved, to the point that hardly any aspect could be found not to have a direct impact on the food industry. Computer technology is also a central force, with computer networks and specialized software providing the support infrastructure to allow for the global movement of the myriad components involved.

The introduction of thousands of new food products each year into retail consumer markets has become normal expectations of consumers. Food manufacturers have been generating new products and line extensions at an amazing pace in an effort to retain retail shelf space and a share of the consumer's food expenditure. New retail food product introductions expanded annually from around 5,500 in 1985 to 16,900 in 1995, before tapering slightly in 1996 and 1997 (Food Marketing Institute, 1997). Figure 2 illustrates categorized food products in a supply network.

Several factors have been considered to be effective as driving forces behind this pace of new introductions. On the demand side, the demand for greater convenience, healthier and safer products, special dietary considerations, product variety, and other product features have been buoyed by greater disposable incomes. On the supply side, retailers have grown their capacities to handle more products, manage categories, and generally become more responsive to even slight changes in consumer preferences through innovations such as EDI, ECR, category management, and customer loyalty programs (Kahn et al., 1997).

Consumers may consider several alternatives in their shopping experience, almost to the point of being overwhelmed. Couponing, merchandising, and advertisement of new food products have kept pace with the number of new introductions. The introduction of new food products has become a strategic tool applied by manufacturers to achieve or retain prime shelf space. Product life cycles for these

Figure 2. Categorized food products in a supply network

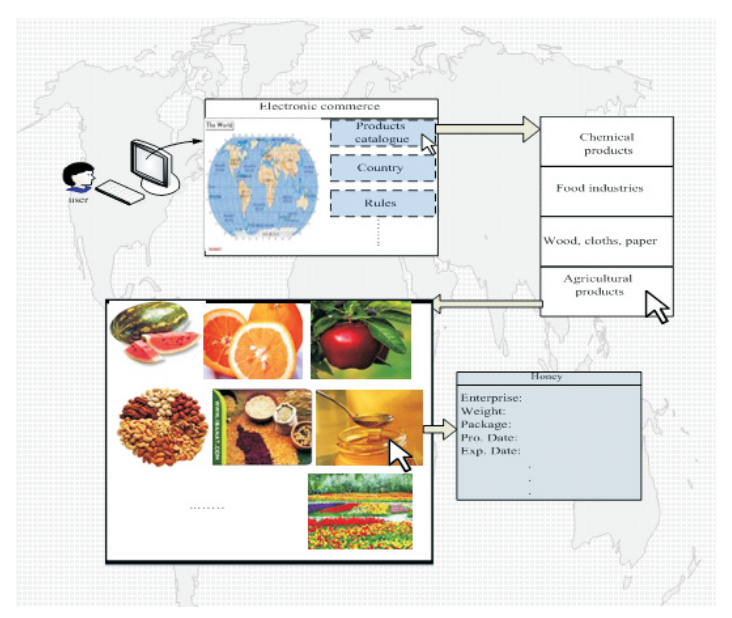


new products are considerably short, with industry sources estimating that $96 \%$ of these new products are no longer on the shelf after one year of their release (Toops, 1996).

Changes in the retail environment, intensified competition among food manufacturers, and shorter product life cycles have raised the significance of focus on new product development (NPD) efficiency. Increasing or changing development costs associated with a variety of regulatory and internal research activities have similarly heightened interest in NPD. Science and technology have changed the manufacturing capabilities in a way that $R \& D$ investment decisions have become very complicated.

\section{Food Supply Chain and Its Importance}

The food supply chain can be defined as a complex network of inputs and outputs which starts from primary farm production and everything related to it, goes through different forms and stages of food processing and preservation, very often associated with long distance travelings, and reaches the end-oflife phase (Swedish Environmental Protection Agency, 1999). Under the conditions of constantly changing environment, the capability of organizations to restructure and respond is of vital importance. A suitable model for this appears to be supply chains. They can contribute to reducing the uncertainties, providing access to information, and improving the reliability and responsiveness.

Supply chains provide better possibilities for problem solving and sharing the associated benefits and burdens. With the growing concern for the environment, a new perspective has been added to supply chains and their environmental managements. Environmental supply chain management can be defined as a "set of supply chain management policies held, actions taken, and relations formed in response to concerns related to natural environment with regard to the design, acquisition, production, distribution, use, reuse and disposal of the firm's goods and services" (Hagelaar and Vorst, 2002).

As all industries and activities, agriculture and food industry contribute to the depletion and contamination of natural resources, and thus create serious environmental impacts. A lot has been done to identify and analyze the aspects and impacts of each of the phases of the food supply chain. It has become apparent, however, that in order to incorporate the environmental concerns in the supply chain management and respond to the rising consumer demands, the environmental aspects could not be dealt with separately at each step of the chain. Therefore, a holistic approach is necessary for the identification and evaluation in the whole food chain as such.

Though realizing that supply chain perspective is important, analyzing it appears to be a difficult task. The reason is the great variability of existing goods requiring different supply chains. The actors, being involved, can also differ considerably (in terms of size of companies, geographical locations, types of business in which they operate). The structure of the chain depends on its objectives and it can change over time, additionally complicating the analysis.

Although there are different drives for the developments in the food supply chain (e.g., globalization of markets, greater consumer choice, consumer and media concerns on safety and environment, changes in eating habits, etc.), the incorporation of environmental thinking in the supply chain management is still limited and mainly considered in the strategies of big, multinational companies. According to Hall (2002), environmental supply chain dynamics take place if there is a channel leader with sufficient channel power over the suppliers, technical competencies, and when specific environmental pressure is exerted. Such pressure can be any external factor affecting the company's environmental policy. Two main areas of pressure were identified as regulatory and non-regulatory. Government measures are usually the primary regulatory pressures and are used for correcting market imperfection, but they are not considered sufficient. Non-regulatory pressures are identified as consumer pressure, customer pressure, environmental pressure groups, disclosure requirements, employees and unions, corporate citizenship (Hall, 2002).

\section{Problem Description and Mathematical Model}

As supply network of food products become more dependent on the efficient movement of products among geographically dispersed facilities, there 
would be more opportunity for disruption. This issue is more significant in food industries.

The development of a robust supply network demands careful attention to both the location of the individual supplier facilities and the opportunities for effective transportation between them. Here, we propose a supply network considering multiple timed-windows. The supplier receives the order and forwards it to depots containing multiple food products. Considering the location of the customers, the depots decide upon sending products in the correct time-windows. The aim is to identify the allocation of orders to depots while satisfying the delivery time and minimizing the transportation cost.

Our proposed model here considers different customers being serviced with one supplier. The supplier provides various products and keeps them in different depots. Each depot uses various types of vehicles to satisfy the orders. All depots are already stationed at the designated locations. Here, we consider a multi time-windows supply network of multi food products with deterministic demands in multi-time periods. A set of vehicles are stationed at each depot and each selected vehicle can transfer various food products based on its capacity. A configuration of the proposed problem is presented in Figure 3.

The mathematical model follows here.

$\begin{array}{ll}P & \text { Set of all food products; } p \in P \\ I & \text { Set of all stationed depots; } I \in I \\ J & \text { Set of all customers; } j \in J \\ T & \text { Set of time periods; } t \in T \\ V & \text { Set of all vehicles; } v \in V \\ D_{j p t} & \quad \begin{array}{l}\text { Demand for food product } p \text { of customer } j \\ \text { at period } t\end{array} \\ T H_{i p} & \begin{array}{l}\text { Maximum throughput of product } p \text { at } \\ \text { depot } i\end{array} \\ C A_{i} & \quad \text { Total capacity of depot } i \\ N_{i v t} & \quad \begin{array}{l}\text { The number of existing vehicles } v \text { in depot } \\ \end{array} \\ V L_{w} & \quad \text { Cat period } t \\ d_{i j} & \text { Distance between depot } i \text { and customer } j\end{array}$

Figure 3. A configuration of the proposed model

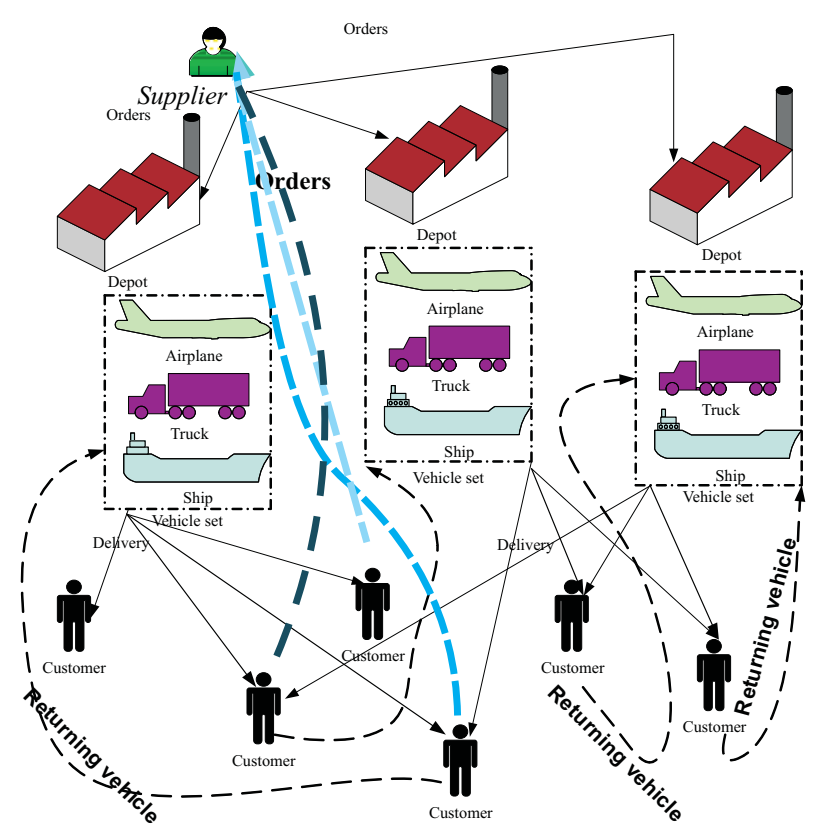

$R V_{j v t} \quad$ The number of returning vehicles $v$ from customer $j$ at period $t$

$M \quad$ Alarge number

$C T_{i j \nu} \quad$ Traveling fixed cost per mile from depot $i$ to customer $j$ using vehicle $v$

$T R T_{i r} \quad$ Traveling time from depot $i$ to customer $j$ using vehicle $v$

$W_{p t} \quad$ Time-window of product $p$ at period $t$

C Cost for every unit of time

\section{Decision variables:}

$x_{i j p v t}:\left\{\begin{array}{l}1 \text { if depot } i \text { is selected to deliver food product } p \text { to customer } j \text { by vehicle } v \text { at period } t \\ 0 \quad \text { otherwise }\end{array}\right.$
$f_{i j p v t} \quad \begin{aligned} & \text { Frequency of traveling for product } p \text { between depot } i \text { and } \\ & \text { customer } j \text { by vehicle } v \text { at period } t\end{aligned}$
$Q P_{i j p t} \quad \begin{aligned} & \text { Quantity of food product } p \text { that can be supplied by depot } i \\ & \text { to customer } j \text { at period } t\end{aligned}$

\section{Objective function:}

Minimize $F=f_{1}+f_{2}$ 
where,

$$
\begin{aligned}
& f_{1}=\sum_{i \in I} \sum_{j \in J} \sum_{p \in P} \sum_{v \in V} \sum_{t \in T} x_{i j p v t} f_{i j p v t} d_{i j} C T_{i j v} \\
& f_{2}=\sum_{i \in I} \sum_{j \in J} \sum_{p \in P} \sum_{v \in V} \sum_{t \in T} x_{i j p v t} T R T_{i j v} C
\end{aligned}
$$

\section{constraint:}

$$
\begin{array}{ll}
\sum_{i \in I} Q P_{i j p t}=D_{j p t} & \forall t, j, p \\
\sum_{j \in J} Q P_{i j p t} \leq T H_{i p} & \forall t, i, p \\
Q P_{i j p t}\left(1-\sum_{v \in V} x_{i j p v t}\right)=0 & \forall t, i, j, p \\
Q P_{i j p t} \geq \sum_{v \in V} x_{i j p v t} & \forall t, i, j, p \\
N_{i v t-1}-\sum_{j \in J} \sum_{p \in P} f_{i j p v t}=N_{i v t} & \forall t, i, v \\
\sum_{j \in J} \sum_{p \in P} f_{i j p v t} \leq N_{i v t-1} & \forall t, i, j, v \\
R V_{j v t-1}=\sum_{p \in P} \sum_{i \in I} f_{i j p v t} & \forall t, j, v \\
R V_{j v t-1}+\sum_{i \in I} N_{i v t}-\sum_{p \in P} \sum_{i \in I} f_{i j p v t}=R V_{j v t} & \forall t, j, v \\
x_{i j p v t} T R T_{i j v} \leq W_{p t} & \forall t, i, j, p, v \\
\int_{\left.\left(\frac{Q P_{i j p t}}{V L_{v p}}\right) x_{i j p v t}\right)_{i j p v t} \in\{0.999}, Q P_{i j p t} \geq 0, f_{i j p v y} & \\
f_{i n t e g e r} & \forall t, i, j, p, v \\
& \\
& \\
& \\
& \\
& \\
&
\end{array}
$$

Equations (1) and (2) are the objective functions corresponding to the total cost and time, respectively. Since time and cost are two separate objectives, we have a multi objective model. To establish a single objective optimization problem, we consider a cost parameter $(C)$ to turn equation (2) into a cost. This way, we can aggregate the two objectives and thus form a single objective function. The constraints (3) guarantee that all customer demands are met, for all food products required and in any period. The constraints
(4) are the flow conservation at depots; they must receive enough food products from supplier in order to meet all the demands. The constraints (5) and (6) ensure that delivery is accomplished by only one vehicle. The constraints (7) represent the number of remaining vehicles at the end of the period. The constraints (8) require that the frequency of traveled vehicles from depot is lower than or equal to its stationed vehicles. The constraints (9) present the flow conservation of returning vehicles from customers. The constraints (10) update the number of returning vehicles. The constraints (11) confine the model to deliver the products to customers using an appropriate vehicle during the time-windows considering the traveling time. The frequencies of traveling between depots and customers are shown by constraints (12). In this equation, the number 0.999 is used to have one unit more than the value of the inner parenthesis in order to have an adequate exact value for frequency of traveling. The constraints (13) require that the variables be binary. The constraints (14) prevent all variables from being negative.

We note that the nonlinear equation (5) can be linearized by using the inequality,

$Q P_{i j p t} \leq M \sum_{v \in V} x_{i j p v t}, \quad \forall t, i, j, p$

where $M$ is a sufficiently large number; since $\sum_{v \in V} x_{i j p v t}$ is equal to 0 or 1 , then (5) implies that $Q P_{i j p t}$ be 0 (when $\left.\sum_{y \in V} x_{i j p v t}=0\right)$ or arbitrary (when $\left.\sum_{v \in V} x_{i j p v t}=1\right)$. The latter is

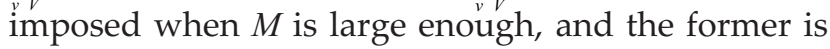
guaranteed by the simultaneous incurred inequalities $Q P_{i j p t} \leq 0$ and $Q P_{i j p t} \geq 0$ (from (14)).

\section{Numerical Illustrations}

Here, we propose a numerical example to show the effectiveness of the proposed mathematical model. The number of customers is three, number of products is three, number of depots is two, and number of vehicles is two. We consider two time periods for the supply chain. The demands for various products by different customers in the two periods are given in Table 1. 
Table 1. The demands for food products

\begin{tabular}{|c|c|c|c|}
\hline & Product 1 & Product 2 & Product 3 \\
\hline First period & & & \\
Customer 1 & 3 & 5 & 6 \\
Customer 2 & 7 & 3 & 5 \\
Customer 3 & 0 & 2 & 3 \\
Second period & & & \\
Customer 1 & 9 & 0 & 8 \\
Customer 2 & 0 & 0 & 3 \\
Customer 3 & 3 & 5 & 7 \\
\hline
\end{tabular}

The transferring costs for vehicles 1 and 2 are 20 and 30, respectively. The numbers of vehicles in different depots are equal to 15 . Also, the capacity of vehicle one for each product is $30,50,20$ and the capacity of vehicle two for each product is 10,15 , and 8 , respectively. The distances between customers and depots are shown in Table 2. The transferring times of vehicles from depots to customers are given in Table 3.

Table 2. Distances between customers and depots

\begin{tabular}{|l|c|c|c|}
\hline & Product 1 & Product 2 & Product 3 \\
\hline Depot1 & 20 & 25 & 10 \\
Depot2 & 10 & 15 & 17 \\
\hline
\end{tabular}

Table 3. Transferring times of vehicles

\begin{tabular}{|l|c|c|}
\hline & Depot 1 & Depot 2 \\
\hline Vehicle 1 & & \\
Customer 1 & 10 & 5 \\
Customer2 & 12 & 7 \\
Customer3 & 5 & 9 \\
Vehicle 2 & & \\
Customer 1 & 15 & 10 \\
Customer 2 & 17 & 12 \\
Customer3 & 10 & 14 \\
\hline
\end{tabular}

The time-windows for each product considering the corresponding time periods are given in Table 4.

Table 4. Time-windows

\begin{tabular}{|l|c|c|c|}
\hline & Period 1 & Period 2 & Period 3 \\
\hline Product1 & 15 & 40 & 35 \\
Product2 & 15 & 35 & 25 \\
Product3 & 10 & 30 & 20 \\
\hline
\end{tabular}

To facilitate the computations, LINGO 9 software package was used. The output for the decision variables are presented in tables 5 and 6 . The best objective value in this status is 1030 .

Table 5. Frequency and depot allocations for food products delivery to customers in various time periods

\begin{tabular}{|c|c|c|c|c|c|c|}
\hline $\boldsymbol{f}$ & $\boldsymbol{X}$ & Depot & Customer & Product & Vehicle & Time \\
\hline 1 & 1 & 1 & 1 & 1 & 1 & 2 \\
1 & 1 & 1 & 1 & 3 & 1 & 2 \\
1 & 1 & 1 & 2 & 1 & 1 & 2 \\
1 & 1 & 1 & 3 & 2 & 1 & 2 \\
1 & 1 & 1 & 3 & 3 & 1 & 2 \\
1 & 1 & 2 & 1 & 2 & 1 & 2 \\
1 & 1 & 2 & 2 & 2 & 1 & 2 \\
1 & 1 & 2 & 2 & 3 & 1 & 2 \\
1 & 1 & 1 & 1 & 1 & 1 & 3 \\
1 & 1 & 1 & 1 & 3 & 1 & 3 \\
1 & 1 & 1 & 3 & 1 & 1 & 3 \\
1 & 1 & 1 & 3 & 2 & 1 & 3 \\
1 & 1 & 1 & 3 & 3 & 1 & 3 \\
1 & 1 & 2 & 2 & 3 & 1 & 3 \\
\hline
\end{tabular}

As seen in Table 5, only vehicle one is used to carry the products to customers. This is due to low transferring cost of vehicle one in comparison with that of vehicle two. The reason that vehicle one has adequate duration to deliver all the demands is the length of the time-windows. We will see in the next section that the variation of time-windows has an effect on the type of vehicle.

Table 6. Quantity of food products to satisfy customers by different depots in various periods

\begin{tabular}{|c|c|c|c|c|}
\hline $\boldsymbol{Q} \boldsymbol{p}$ & Depot & Customer & Product & Time \\
\hline 3 & 1 & 1 & 1 & 2 \\
6 & 1 & 1 & 3 & 2 \\
7 & 1 & 2 & 1 & 2 \\
2 & 1 & 3 & 2 & 2 \\
3 & 1 & 3 & 3 & 2 \\
5 & 2 & 1 & 2 & 2 \\
3 & 2 & 2 & 2 & 2 \\
5 & 2 & 2 & 3 & 2 \\
9 & 1 & 1 & 1 & 3 \\
8 & 1 & 1 & 3 & 3 \\
3 & 1 & 3 & 1 & 3 \\
5 & 1 & 3 & 2 & 3 \\
7 & 1 & 3 & 3 & 3 \\
3 & 2 & 2 & 3 & 3 \\
\hline
\end{tabular}




\section{Discussion}

Here, we investigate the flexibility of the mathematical model over variations of input data; that is, we perform sensitivity analysis on decision variables changing the input data. First, we change the time-windows as given in Table 7.

Table 7. Time-windows

\begin{tabular}{|l|c|c|c|}
\hline & Period 1 & Period 2 & Period 3 \\
\hline Product1 & 13 & 10 & 11 \\
Product2 & 9 & 12 & 12 \\
Product3 & 10 & 11 & 10 \\
\hline
\end{tabular}

We solved the new problem using the new timewindows. The frequency of the vehicles and the allocated depots to deliver food products to customers are given in Table 8.

Table 8. Frequency and depot allocations for food products delivery to customers in various time periods

\begin{tabular}{|c|c|c|c|c|c|c|}
\hline $\boldsymbol{f}$ & $\boldsymbol{X}$ & Depot & Customer & Product & Vehicle & Time \\
\hline 1 & 1 & 1 & 1 & 1 & 1 & 2 \\
1 & 1 & 1 & 1 & 3 & 1 & 2 \\
1 & 1 & 1 & 2 & 1 & 1 & 2 \\
1 & 1 & 2 & 1 & 2 & 2 & 2 \\
1 & 1 & 2 & 2 & 3 & 2 & 2 \\
1 & 1 & 2 & 2 & 3 & 1 & 2 \\
1 & 1 & 2 & 3 & 2 & 1 & 2 \\
1 & 1 & 2 & 3 & 3 & 1 & 2 \\
1 & 1 & 1 & 1 & 1 & 1 & 3 \\
1 & 1 & 1 & 1 & 3 & 1 & 3 \\
1 & 1 & 1 & 3 & 1 & 2 & 3 \\
1 & 1 & 1 & 3 & 3 & 2 & 3 \\
1 & 1 & 2 & 2 & 3 & 2 & 3 \\
1 & 1 & 2 & 3 & 2 & 1 & 3 \\
\hline
\end{tabular}

We observe that for the new data, vehicle two is allocated to deliver food products rather than vehicle one. This is due to smaller values for the timewindows. Also, the quantity of food products to be delivered to the customers is reported in Table 9.

The best objective value here is 11480 .

In another case, we increased that the distances between depots and customers to larger amounts as in Table 10, and also set the capacities of vehicle one for each product to be 5, 5, 2 and the capacities of vehicle two for each product to be 5,7 , and 8 , respectively.
Table 9. Quantity of food products to satisfy customers by different depots in various periods

\begin{tabular}{|l|c|c|c|c|}
\hline $\boldsymbol{Q} \boldsymbol{p}$ & Depot & Customer & Product & Time \\
\hline 3 & 1 & 1 & 1 & 2 \\
6 & 1 & 1 & 3 & 2 \\
7 & 1 & 2 & 1 & 2 \\
2 & 1 & 3 & 2 & 2 \\
3 & 1 & 3 & 3 & 2 \\
5 & 2 & 1 & 2 & 2 \\
3 & 2 & 2 & 2 & 2 \\
5 & 2 & 2 & 3 & 2 \\
9 & 1 & 1 & 1 & 3 \\
8 & 1 & 1 & 3 & 3 \\
3 & 1 & 3 & 1 & 3 \\
5 & 1 & 3 & 2 & 3 \\
7 & 1 & 3 & 3 & 3 \\
3 & 2 & 2 & 3 & 3 \\
\hline
\end{tabular}

The best objective value here is 11480 .

Table 10. Distances between customers and depots

\begin{tabular}{|l|c|c|c|}
\hline & Customer 1 & Customer 2 & Customer 3 \\
\hline Depot1 & 150 & 175 & 160 \\
Depot2 & 150 & 145 & 167 \\
\hline
\end{tabular}

Then, solving the new mathematical problem, the frequency of the traveling rises as in Table 11.

Table 11. Frequency and depot allocations for food products delivery to customers in various time periods

\begin{tabular}{|c|c|c|c|c|c|c|}
\hline $\boldsymbol{f}$ & $\boldsymbol{X}$ & Depot & Customer & Product & Vehicle & Time \\
\hline 1 & 1 & 1 & 1 & 1 & 1 & 2 \\
3 & 1 & 1 & 1 & 3 & 1 & 2 \\
2 & 1 & 1 & 2 & 1 & 2 & 2 \\
1 & 1 & 1 & 2 & 3 & 2 & 2 \\
1 & 1 & 1 & 3 & 3 & 2 & 2 \\
1 & 1 & 2 & 1 & 2 & 2 & 2 \\
1 & 1 & 2 & 2 & 2 & 2 & 2 \\
1 & 1 & 2 & 3 & 2 & 1 & 2 \\
2 & 1 & 1 & 1 & 1 & 1 & 3 \\
1 & 1 & 1 & 2 & 3 & 2 & 3 \\
1 & 1 & 1 & 3 & 1 & 2 & 3 \\
1 & 1 & 1 & 3 & 3 & 2 & 3 \\
1 & 1 & 2 & 1 & 3 & 2 & 3 \\
1 & 1 & 2 & 3 & 2 & 1 & 3 \\
\hline
\end{tabular}

Also, the quantities of food products to be delivered to customers are reported in Table 12. 
Table 12. Quantity of food products to satisfy customers by different depots in various periods

\begin{tabular}{|c|c|c|c|c|}
\hline $\boldsymbol{Q} \boldsymbol{p}$ & Depot & Customer & Product & Time \\
\hline 3 & 1 & 1 & 1 & 2 \\
6 & 1 & 1 & 3 & 2 \\
7 & 1 & 2 & 1 & 2 \\
5 & 1 & 2 & 3 & 2 \\
3 & 1 & 3 & 3 & 2 \\
5 & 2 & 1 & 2 & 2 \\
3 & 2 & 2 & 2 & 2 \\
2 & 2 & 3 & 2 & 2 \\
9 & 1 & 1 & 1 & 3 \\
3 & 1 & 2 & 3 & 3 \\
3 & 1 & 3 & 1 & 3 \\
7 & 1 & 3 & 3 & 3 \\
8 & 2 & 1 & 3 & 3 \\
5 & 2 & 3 & 2 & 3 \\
\hline
\end{tabular}

The best objective value in this case is 111850 .

The graphical presentation of the variations in frequency of vehicles for different cases, i.e., the first case in which everything was fixed, the second case in which we decreased the time-windows, and the third case in which we increased the distance between depots and customers, is shown in Figure 3. Clearly, for the third case, where we considered distances to increase between depots and customers, the frequencies turned to rise.

Figure 3. Variations in frequency of the vehicles in the three cases

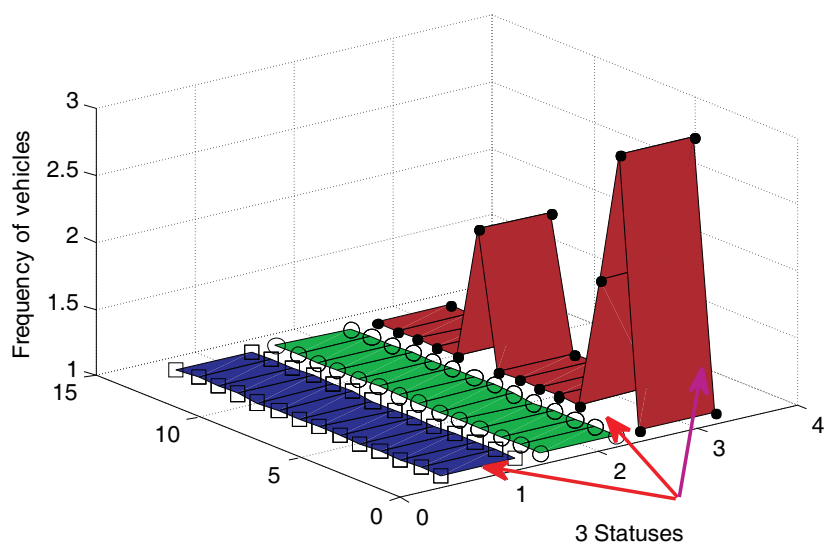

We configure another graphical presentation for the variations of product quantity in different cases, i.e., the first case in which everything was fixed, the second case in which we decreased the time-windows, and the third case in which we changed the distances between depots and customers, as shown in Figure 4.

Figure 4. Variation in product quantity in three cases

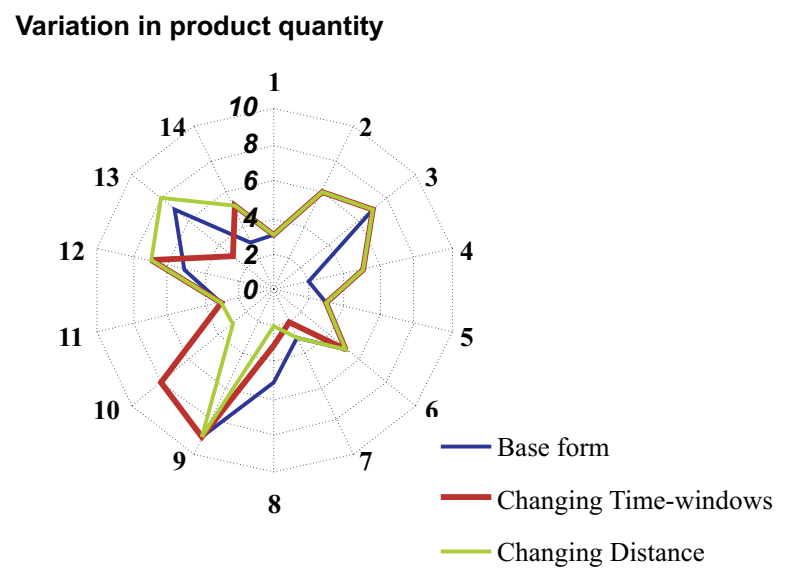

\section{Conclusions}

We proposed a supply network in which one supplier would provide various food products for customers in different time periods. The contribution of the proposed model is in its flexibility on vehicles and depots. The aim was to minimize the cumulative sum of cost and time of the order to delivery process. The validity of the model was tested in a numerical illustration. An illustrating sensitivity analysis was worked out to show the flexibility of the proposed mathematical model.

\section{Acknowledgements}

The first author thanks Sari Agricultural Sciences and Natural Resources University, the second author thanks Mazandaran University of Science and Technology and the last author thanks Research Council of Sharif University of Technology for supporting this work.

\section{References}

Apaiah, K.R., Hendrix, E.M.T., Meerdink, G. and Linnemann, A. R. (2005). Qualitative methodology for efficient food chain design. Trends in Food Science and Technology 16(5), pp. 204-214. 
Beamon, B.M. (1998). Supply chain design and analysis: Models and methods. International Journal of Production Economics 55, pp. 281-294.

Bernstein, F. and Federgruen, A. (2005). Decentralized supply chains with competing retailers under demand uncertainty. Management Science 51(1), pp. 18-29.

Bonanno, G. and Vickers, J. (1988). Vertical separation. Journal of Industrial Economics 36, pp. 257-265.

Cachon, G. and Lariviere, M. (2005). Supply chain coordination with revenue sharing contracts. Management Science 51(1), pp. 30-44.

Che, Z.G., Che, Z.H. and Hsu, T.A. (2009). Cooperator selection and industry assignment in supply chain network with line balancing technology. Expert Systems with Applications 36, pp. 10381-10387.

Christopher, W., Craighead, G., Hult, T.M. and Ketchen, D.J. (2009). The effects of innovation-cost strategy, knowledge, and action in the supply chain on firm performance. Journal of Operations Management 27, pp. 405-421.

Coughlan, A.T. (1985). Competition and cooperation in marketing channel choice: Theory and application. Marketing Science 4 (Spring), pp. 110-129.

Food Marketing Institute, "Food Industry Outlook", (1997).

Francasa, D. and Minner, S. (2009). Manufacturing network configuration in supply chains with product recovery. Omega37, pp. 757-769.

Hagelaar, G. and van der Vorst, G. (2002). Environmental supply chain management: Using LCA to structure supply chains and Wageningen. International Food And Agribusiness Management Review [Online]. Available in: http://www.sciencedirect.com/.

Hall, J. (2002). Environmental supply chain dynamics [Online]. Available in: http://www.sciencedirect.com/.

Jeuland, A.P. and Shugan, S.M. (1983). Managing channel profits. Marketing Science 2(3), pp. 239-272.

Kahn, B.,E. and McAlister, L. (1997). Grocery Revolution: The New Focus on the Consumer, Addison-Wesley Press, Reading, MA.
McGuire, T.W. and Staelin, R. (1983). An industry equilibrium analysis of downstream vertical integration. Marketing Science 2(2), pp. 161-191.

Moorthy, K. (1988). Strategic decentralization in channels. Marketing Science 7(4), pp.335-355.

Pan, A., Leung, S.Y.S., Moon, K.L. and Yeung, K.W. (2009). Optimal reorder decision-making in the agent-based apparel supply chain. Expert Systems with Applications 36, pp. 8571-8581.

Pasternack, B.A. (1985). Optimal pricing and returns policies for perishable commodities. Marketing Science 4(2), pp. 166-176.

Swedish Environmental Protection Agency (1999). A sustainable food supply chain: A Swedish case study. Stockholm: Elanders Gotab.

Tijskens, L.M.M., Koster, A.C. and Jonker, J.M.E. (2001). Concepts of chain management and chain optimization. In Tijskens, L.M.M., Hertog, M.L.A.T.M., \& Nicolai, B.M. (Eds.), Food process modeling. Woodhead, pp. 145-162.

Toops, D. (1996). Against all odds, Food Processing, January, pp. 16-17.

Trienekens, J.H. and Omta, S.W. F. (2001). Paradoxes in food chains and networks. In Proceedings of the Fifth International Conference on Chain and Network Management in Agribusiness and the Food Industry, The Netherlands: Noordwijk, pp.452-463.

van der Vorst, J. G. A. J. (2000). Effective food supply chains. Generating, modeling and evaluating supply chain scenarios. Wageningen: Wageningen University, pp. 171-190.

Xu, N. and Nozick, L. (2009). Modeling supplier selection and the use of option contracts for global supply chain design. Computers $\mathcal{E}$ Operations Research 36, pp. 2786-2800.

Zuurbier, P.J.P., Trienekens, J.H. and Ziggers, G.W. (1996). Verticale Samenwerking. Deventer: Kluwer Bedrijfswetenschappen.

Zeynab Raftani-Amiri is an Assistant Professor at Sari Agricultural Sciences and Natural Resources University, Department of Food Science and Technology, Sari, Iran. Her research interests are food technology and optimization. She has published 12 research papers in international journals and conferences.

Hamed Fazlollahtabar is head of Incubator \& Technology at Mazandaran University of Science and Technology, Babol, Iran. He received Doctorate awarded from the Gulf University of Science and Technology in Quantitative Approaches in Electronic Systems. He is in the editorial board of WASET (World Academy of Science Engineering 
Technology) Scientific and Technical Committee on Natural and Applied Sciences, reviewer committee of International Conference on Industrial and Computer Engineering (CIE), and member of the International Institute of Informatics and Systemics (IIIS). He is also a reviewer in International Journals. His research interests are optimization in electronic-systems and information technology management. He has published 59 research papers in book chapter, international journals and conferences.

Nezam Mahdavi-Amiri is a full professor of Mathematical Sciences at Sharif University of Technology. He received his Ph.D. from the Johns Hopkins University in Mathematical Sciences. He is vice president of the Iranian Operations Research Society. He is on the editorial board of several international mathematical and computing journals in Iran, including Bulletin of Iranian Mathematical Society, The CSI Journal of Computer Science and Engineering, and Journal of Iranian Operations Research Society. His research interests include Optimization, Numerical Analysis and Scientific Computing, Matrix Computations, Fuzzy Modeling and Computing. 